UCRL-JC-124728

CONF-9607/39--3

\title{
The Transuranium Elements: From Neptunium and Plutonium to Element 112
}

\author{
Professor Darleane C. Hoffman \\ Lawrence Livermore National Laboratory \\ G. T. Seaborg Institute for Transactinium Science \\ Isotope Sciences Division \\ RECEIVED \\ SEP 23 996 \\ OSTI
}

This paper was prepared for submittal to the

Conference Proceedings

NATO Advanced Study Institute on "Actinides and the Environment"

Chania, Crete, Greece

July 7-19, 1996

July 26，1996

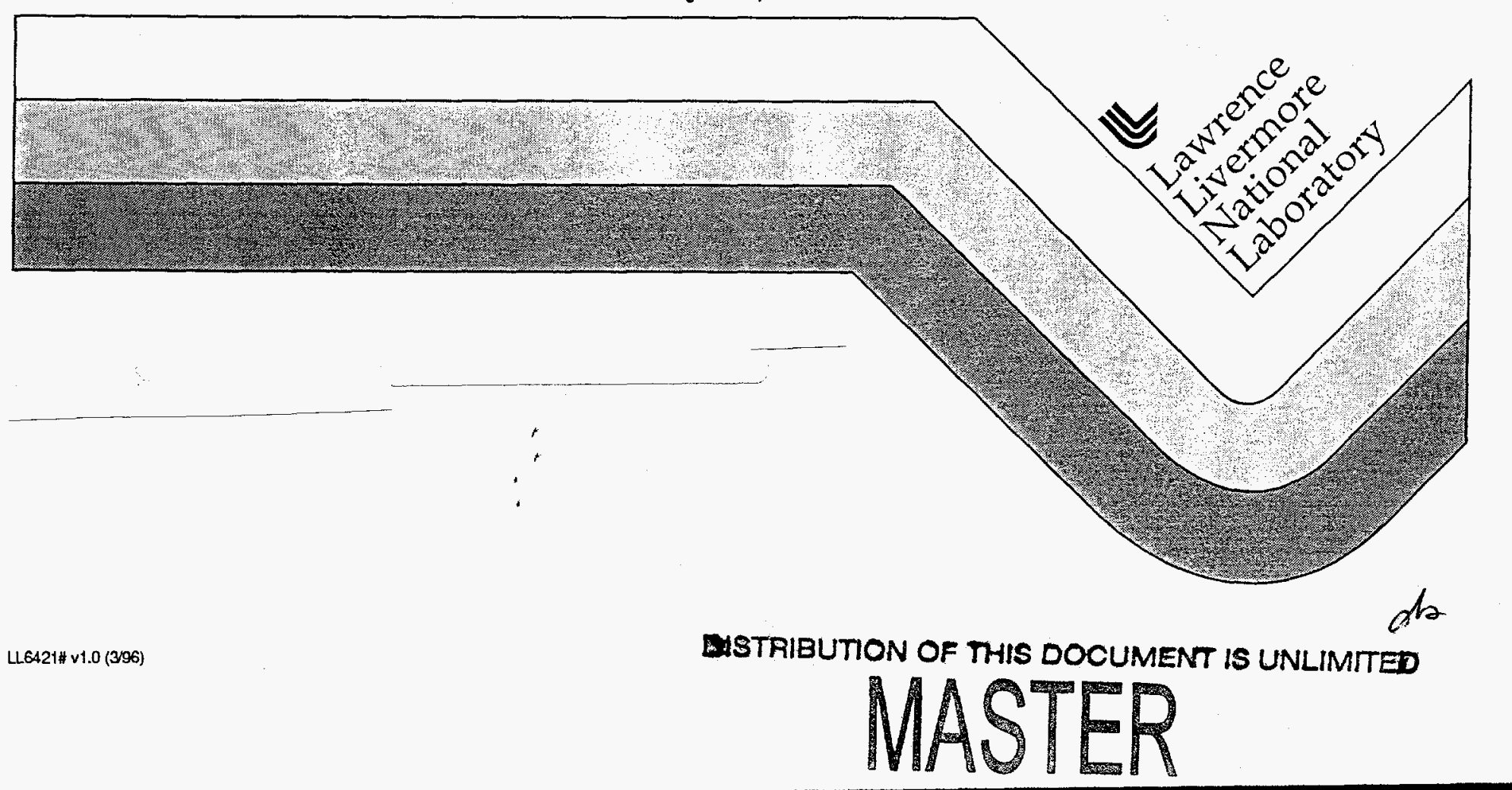




\section{DISCLAIMER}

This document was prepared as an account of work sponsored by an agency of the United States Government. Neither the United States Government nor the University of California nor any of their employees, makes any warranty, express or implied, or assumes any legal liability or responsibility for the accuracy, completeness, or usefulness of any information, apparatus, product, or process disclosed, or represents that its use would not infringe privately owned rights. Reference herein to any specific commercial product, process, or service by trade name, trademark, manufacturer, or otherwise, does not necessarily constitute or imply its endorsement, recommendation, or favoring by the United States Government or the University of California. The views and opinions of authors expressed herein do not necessarily state or reflect those of the United States Government or the University of California, and shall not be used for advertising or product endorsement purposes. 


\section{DISCLAIMER}

Portions of this document may be illegible in electronic image products. Images are produced from the best available original document. 


\title{
THE TRANSURANIUM ELEMENTS: FROM NEPTUNIUM AND PLUTONIUM TO ELEMENT 112
}

\author{
Darleane C. Hoffman \\ Nuclear Science Division \& Chemistry Department, University of \\ California, Berkeley, CA 94720 \& G. T. Seaborg Institute for \\ Transactinium Science, MS-L231, LLNL, Livermore, CA 94550.
}

\section{Introduction}

Beginning in the mid-1930's, spurred by the discovery of the neutron by Chadwick in 1932 and artificial radioactivity by the Joliot-Curies in 1934, the new breed of nuclear scientists (including both chemists and physicists) became intrigued with the prospect of synthesizing new "artificial" elements not found in nature. Uranium, the heaviest known element, had been discovered in 1789 and yet it was to be nearly 150 years before the ancient alchemists' dream of transmutation was achieved with the synthesis of the first transuranium element, neptunium, in 1940. Over the past six decades, 20 transuranium elements have been produced. (See Figure 1 which shows the current periodic table as of mid-1996).

\section{Nuclear Fission}

Inextricably intertwined with the discovery of transuranium elements has been the discovery and study of nuclear fission. Fermi and coworkers began experiments in 1934 to try to produce element 93 by bombarding uranium with neutrons to give ${ }^{239} \mathrm{U}$ which they expected would beta decay to produce ${ }^{239} 93$. Based on the then accepted periodic table, they believed element 93 should behave like the lighter homologs manganese and rhenium (see Figure 2 which shows periodic table from before World War II). They performed a chemical separation designed to separate element 93 with a precipitate of rhenium sulfide and found a 13-minute activity which in a paper published in 1934 [1] they tentatively assigned to element 93. Ida Noddack (a discoverer of rhenium ) published a paper [2] soon after in which she expressed her doubt about their assignment and suggested that the bombarded nuclei might have disintegrated into several larger fragments! In subsequent years, Hahn, Meitner, and Strassmann [3] in Berlin seemed to confirm these results and reported other isotopes of eka-rhenium as well as of eka-osmium, -iridium, and -platinum. However, there were many unsettling aspects about these results and in 1938 Curie and Savitch [4] found a 3.5-hour activity with the chemical properties of a rare earth, but they were unable to explain this and it was at first greeted with some skepticism by the Berlin group. Finally, Hahn and Strassmann decided to perform their own experiments and found several new activities 
which they attributed to radium and actinium istopes and isomers. Meitner (now in Stockholm) at least, found these results unsatisfying: there were now some 16 new species that originated with $238 \mathrm{U}$, including multiple isomerism, and beta-decay energies which were too high for the measured half-lives! Furthermore, the yields were markedly enhanced when slow neutrons were used, making the postulated $(n, \alpha)$ reactions to make thorium which then $\alpha$-decayed to $R a(A c)$ isotopes energetically impossible. Meitner urged that they re-examine the experiments and it was then that Hahn and Strassmann [5] began the series of experiments which culminated in the discovery of nuclear fission by showing that the activities attributed to $\mathrm{Ra}, \mathrm{Ac}$, and $\mathrm{Th}$ actually followed the chemistry of $\mathrm{Ba}, \mathrm{La}$, and $\mathrm{Ce}$ !! But they still hesitated to believe their results, and stated, "As nuclear chemists, being in some respects close to physics, we have not yet been able to take this leap which contradicts all previous experiences in nuclear physics. It could still perhaps be that a series of unusual coincidences have given us deceptive results."

However, during the Christmas holidays of 1938, Meitner together with her nephew, physicist Otto Robert Frisch, who had come to visit her in Sweden, unraveled the puzzle. They worked out all the essential features of nuclear fission based on the liquid drop model and the masses involved. Upon returning to Copenhagen, Frisch spoke with Niels Bohr who immediately agreed with their interpretation and they proceeded to submit a letter to Nature on "Disintegration of Uranium by Neutrons: A New Type of Nuclear Reaction" [6]. In this elegant paper, in just over a page, they outlined the essentials of the theory of nuclear fission, including the total energy released and the recoil energy of the fission fragments, which Frisch [7] quickly detected experimentally .

\section{The Actinide Elements}

\subsection{NEPTUNIUM (93) AND PLUTONIUM (94)}

Now there were no more transuranium elements, as Fermi's transuranium elements could all be attributed to fission products which had obscured the activity of the new element 93. Seemingly, all of the nuclear scientists in the world then set out to investigate the new phenomenon and in Berkeley, Edwin M. McMillan, while investigating the recoil of fission products produced in the irradiation of a thin layer of ${ }^{238} \mathrm{U}$ with slow neutrons, found a 2.3 -day activity which did not recoil out and appeared to be the daughter of 23 -minute ${ }^{239} \mathrm{U}$. In the spring of 1940 he and Philip H. Abeison chemically separated and identified [8] the new element $\mathrm{Np}$.

$$
{ }^{238} \mathrm{U}+\mathrm{n} \longrightarrow{ }^{239} \mathrm{U}+\gamma ;{ }^{239} \mathrm{U} \stackrel{\text { B.23 minutes }}{2}{ }^{239} \mathrm{~Np} \stackrel{\text { B.2.3d }}{\longrightarrow} 23994
$$

It was obvious to them that the new element should beta decay to the same mass number of element 94 , but they were unable to identify it. Bombardments were begun with deuterons in the 60-Inch Cyclotron at Berkeley, but McMillan was called away and Glenn T. Seaborg wrote to ask him whether he and his graduate student Arthur C. Wahl 
and a fellow instructor Joseph W. Kennedy should carry on this research. He agreed and in December 1940 they detected alpha decay of an activity which grew in to the ehemically separated neptunium fraction and had a half-life estimated to be about 50 years.

$$
{ }^{238} \mathrm{U}+{ }^{2} \mathrm{H} \longrightarrow{ }^{238} \mathrm{~Np}+2 \mathrm{n} ;{ }^{238} \mathrm{~Np} \longrightarrow{ }^{\beta}{ }^{238} \mathrm{Pu}(-50 \text { years })
$$

They sent a short note to Washington describing their results, but didn't consider they had sufficient proof to claim discovery until finally on the night of February 23, 1941, Art Wahl oxidized it with peroxydisulphate $+\mathrm{Ag}^{+1}$ and it was shown to have properties similar to $U$ but not to Os as suggested earlier. This was also communicated to Washington, but these two articles were not published until $1946[9,10]$. Soon after, a $1.2 \mathrm{~kg}$ sample of uranyl nitrate was irradiated with neutrons in the 60-Inch Cyclotron for two days in order to produce enough ${ }^{239} \mathrm{~Np}$ so that after its purification it would decay to form $0.5 \mu \mathrm{g}$ of ${ }^{239} \mathrm{Pu}$ whose half-life was calculated to be about 30,000 years. Shortly after in March, 1941, it was shown that its fission cross section with slow neutrons was about $50 \%$ greater than for $235 \mathrm{U}$, which was later published by Kennedy, Seaborg, Segrè, and Wahl [11]. This information formed the basis for the U. S. wartime Plutonium Project at the Metallurgical Laboratory of the University of Chicago whose mission was to develop a method for the production of $\mathrm{Pu}$ in quantity and for its chemical separation on a large scale.

Elements 93 and 94 were named neptunium $(\mathrm{Np})$ and plutonium ( $\mathrm{Pu}$ ), because uranium was originally named after Uranus, and Neptune and Pluto are the next planets beyond Uranus, hence, the names neptunium and plutonium. (For more details on these discoveries and naming, see G. T. Seaborg, [12].)

\subsection{AMERICIUM (95) THROUGH FERMIUM (100)}

All of these elements were produced first either via neutron or helium-ion bombardments in the years between 1944 and 1955. Initially, unsuccessful attempts were made to produce and chemically separate elements 95 and 96 believing that they were part of a uranide series with $U$ as the prototype and would have chemical properties similar to $\mathrm{Pu}, \mathrm{Np}$, and U. Finally, in 1944 Seaborg proposed in an article published later in Chemical \& Engineering News [13] that maybe this new series should start at thorium with actinium as the prototype, as shown in Figure 3. Then elements 95 and 96 might have properties similar to Eu and Gd and, therefore, could be oxidized beyond the III state only with great difficulty. Element 96 was produced [13] in 1944 via the ${ }^{239} \mathrm{Pu}(\alpha, \mathrm{n}){ }^{242} 96$ reaction at the Berkeley 60 -Inch Cyclotron and was shipped to the Met Lab for processing. In 1945, 24195 was produced by A. Ghiorso et al. [14] by multiple neutron capture in ${ }^{239} \mathrm{Pu}$ bombarded in a reactor. The names americium and curium were proposed for elements 95 and 96 by analogy to europium and gadolinium which were named after Europe and after Johan Gadolin, a Finnish rareearth chemist. These two elements were exceedingly difficult to separate from each other until the development of ion-exchange techniques which were also to be widely used in the separation of subsequent actinides. 
Next came the discovery of berkelium (97) in 1949 produced via the ${ }^{241} \mathrm{Am}(\alpha$, $2 \mathrm{n}) 24397$ (4.5 h) reaction [15] and californium (98) produced [16] via the ${ }^{242} \mathrm{Cm}(\alpha$, n) 24598 ( $44 \mathrm{~min}$ ) reaction at the Berkeley 60 -Inch Cyclotron. Key to discovery of Bk was removal of the large amount of Am target material by oxidizing it to the hexapositive state and subsequent elution of the Bk from a cation exchange column just ahead of $\mathrm{Cm}$. The californium (98) experiment used a few micrograms of the highly radioactive target ${ }^{242} \mathrm{Cm}$ and the identification of $\mathrm{Cf}$ was made with a total of only about 5,000 atoms using elution from a cation exchange resin column to identify it. The names berkelium and californium were chosen to honor the city and state of discovery.

Although most of the discoveries of the transuranium elements were carefully planned based on the best available knowledge concerning chemical and nuclear properties, elements 99 and 100 were synthesized in a most dramatic, unplanned, and unexpected manner in the first U.S. thermonuclear device "Mike" tested at Eniwetok in November, 1952. Because of the enormous, nearly instantaneous high neutron flux generated in its detonation (see Figure 4) at least 17 neutrons were successively captured in the ${ }^{238} \mathrm{U}$ to produce isotopes through ${ }^{255} \mathrm{U}$. In subsequent tests, ${ }^{257} \mathrm{Fm}$ was detected, indicating capture of at least 19 neutrons! These short-lived uranium isotopes then beta-decayed to the more stable, higher $Z$ elements as shown in Figure 5 . Early analyses at Los Alamos Scientific Laboratory and Argonne National Laboratory to determine the performance of the test showed the first evidence that something truly unexpected had occurred when the new very neutron-rich isotopes ${ }^{244} \mathrm{Pu}(-80$ million years, still the longest known isotope of $\mathrm{Pu}$ ) was found in mass spectrometric analyses, and ${ }^{246} \mathrm{Pu}$ (11 d) was found in Pu samples separated from the debris collected after the test. This led the Berkeley group to join the other two Labs in a search for trans-Cf isotopes. Eventually tons of coral were laboriously processed and the 20-day 25399 and $20-\mathrm{h} 255100$ were positively identified using the technique of elution from a cationexchange resin column. Although this "discovery" was unplanned, the previous experience with the ion exchange elution technique, the prediction that Es and Fm should be +3 's, and their predicted elution positions based on their positions in the actinide series, were instrumental in the discoveries. After much discussion, the names einsteinium (Es) and fermium (Fm), after the great scientists Albert Einstein and Enrico Fermi, were chosen for these elements. (It should be noted that Einstein and Fermi were both still alive when these names were proposed.) After later declassification, the discovery of Es and Fm was published in 1955 [17]. Although subsequent attempts were made to produce still heavier elements in underground nuclear tests, ${ }^{257} \mathrm{Fm}$ was the heaviest isotope which could be synthesized and detected using neutron-capture reactions. (See Figure 5.)

\subsection{THE END OF THE ACTINIDES: MENDELEVIUM (101) THROUGH IAWRENCIUM (103)}

Element 101 is the first element which was produced and identified an "atom-at-a-time" using a target of only about $10^{9}$ atoms of ${ }^{253}$ Es produced by irradiation of $\mathrm{Pu}$ in the Materials Testing Reactor. The $(\alpha, n)$ reaction at the 60 -Inch Cyclotron was used [18] in 1955 to make 256101 . For the first time in this type of experiment, the "recoil" 
technique in which the reaction products recoiling out of the very thin target are collected on a "catcher" foil. The foil is then quickly removed and chemically processed without destroying the very precious target so it can be used over and over again. Only about one atom per irradiation was expected. The ion exchange method with alpha-hyroxyisobutyrate as eluant was used and 5 spontaneous fissions (SFs) were observed in the 101 position and 8 in the 100 position. From the half-lives and other evidence it was established that $256_{101}$ decays by electron capture to $256_{100}$ which then decays by SF. The name mendelevium was suggested in honor of Dimitri Mendeleev, the great Russian chemist who formulated and pioneered the use of the periodic table of the elements to predict chemical properties of unknown elements.

The discovery of element 102 was first reported in 1957 by an international group [19] of scientists from Argonne National Laboratory in the U. S., the Atomic Energy Research Establishment in Harwell, England and the Nobel Institute of Physics in Stockholm. They irradiated a ${ }^{244} \mathrm{Cm}$ target with ${ }^{13} \mathrm{C}$ ions at the Cyclotron at the Nobel Institute and detected a 10 -minute activity which decayed via $8.5-\mathrm{MeV}$ alpha emission, which they attributed to element 102 . The assignment was based on its elution from an ion-exchange column with alpha-hydroxyisobutyrate in the expected position for element 102, i.e., just after the free column volume and they suggested the name nobelium in honor of Alfred Nobel. Researchers at both Berkeley [20] and the Kurchatov Institute in Moscow [21] were unable to confirm this result and much later experiments at Berkeley [22] showed that, in fact, the most stable oxidation state of element 102 in aqueous solution was $2^{+}$and, therefore, would not have eluted in the position expected for a trivalent actinide. For a more complete review of the chemistry of the chemistry of the elements heavier than fermium (100), see Refs. 23 and 24. Experiments at Berkeley in 1958 by Ghiorso et al. [25] identified $254102(55 \mathrm{~s})$ in the reaction of ${ }^{246} \mathrm{Cm}$ with ${ }^{12} \mathrm{C}$ ions based on chemical identification of its ${ }^{254} 102$ (30 $\mathrm{min}$ ) daughter activity. In direct counting in recoil experiments, a 3-s half-life was erroneously assigned to this isotope, but it was later found to be due to $252102(2.3 \mathrm{~s}$ ) produced from ${ }^{244} \mathrm{Cm}$ in the target. In 1958 in the reaction of $239 \mathrm{Pu}$ with $16 \mathrm{O}$ ions, Flerov et al. [26] at the Kurchatov Institute reported producing an $8.9-\mathrm{MeV}$ alphaemitter with a 2 to $40 \mathrm{~s}$ half-life which they attributed to 102. Later (1964) Donets et al. [27] produced 256102 and chemically identified its $252 \mathrm{Fm}$ daughter. Subsequently, at Dubna, the correct measurement of the half-life of ${ }^{254} 102$ was made. Thus, credit for discovery of element 102 was really shared by the Berkeley group and Donets et al. at Dubna. Since the name nobelium (No) was already in common use, the Berkeley group suggested that this name be retained.

Element 103 was first produced and identified at the Berkeley HILAC in 1961 by Ghiorso et al. [28] in the following reaction:

$$
{ }^{249-252} \mathrm{Cf}\left({ }^{10,11_{\mathrm{B}, \mathrm{xn})}}{ }^{257,258} 103(\mathrm{Lr}) \underline{8.6-\mathrm{MeV} \alpha .-8 \mathrm{~s}}\right\rangle
$$

The recoiling atoms were caught on metalized Mylar tape which was moved past a series of alpha detectors which recorded activity from a few new 257,258103 nuclei with half-lives of seconds or less. They suggested the name lawrencium after E. O. Lawrence, the inventor of the cyclotron and the founder of the Berkeley Radiation 
Laboratory. The name was accepted by IUPAC, but the original symbol of Lw was changed to Lr.

Later, Donets et al. [29] in 1965 used a double-recoil technique to positively identify the atomic number of element 103 by linking its decay, via either electron capture (ec) followed by alpha decay, or by alpha decay followed by ec, to its known granddaughter, ${ }^{252} \mathrm{Fm}$, which decays with a half-life of 25 hours. This daughter was identified both chemically and by its characteristic alpha decay. Thus, some credit for discovery of element 103 should be shared by Donets et al.

$$
{ }^{243} \mathrm{Am}\left({ }^{18} \mathrm{O}, 5 \mathrm{n}\right){ }^{256} \mathrm{Lr} \stackrel{\alpha, 45 \mathrm{~s}}{\longrightarrow}{ }^{252} \mathrm{Md}(101) \stackrel{\mathrm{ec}, 2 \mathrm{~m}}{\longrightarrow}{ }^{252} \mathrm{Fm} \text { (known) }
$$

Figure 6 shows all the currently known isotopes of $\mathrm{Lr}$ and the heavier elements. In 1970, Silva et al. [30] used the 26-s ${ }^{256_{L r}}$ to perform chemical studies which established that the most stable oxidation state of $\mathrm{Lr}$ in aqueous solution is $3+$, as expected from Seaborg's actinide hypothesis, which also predicted that with filling of the $5 f$ shell $\mathrm{Lr}$ should end the actinide series.

\section{The Transactinide Elements}

\subsection{RUTHERFORDIUM (ELEMENT 104) THROUGH SEABORGIUM (ELEMENT 106)}

\subsubsection{Rutherfordium (Element 104)}

Controversy has surrounded the discovery of elements 104 and 105 ever since the very first reports; for a comprehensive discussion of the claims and counterclaims and a bibliography of all the published literature, see Hyde, Hoffman, and Keller [31]. In 1964, Flerov et al. [32] reported detection of a 0.3-s spontaneously fissioning activity produced at the heavy ion cyclotron at the Joint Institutes of Nuclear Research (JINR) at Dubna in the following reaction:

$$
{ }^{242} \mathrm{Pu}\left({ }^{22} \mathrm{Ne}, 4 \mathrm{n}\right){ }^{260}{ }_{104}(\sigma-0.2 \mathrm{nb}) \stackrel{\mathrm{SF} .0 .3 \mathrm{~s}}{\longrightarrow}(58 \mathrm{SFs})
$$

Recoils were collected on a nickel conveyer belt which was moved past special phosphate glass detectors where the fission events were recorded. From the distribution of etched tracks and the known speed of the belt the half-life could be deduced. The bombarding energy of the Ne projectiles was also varied and the excitation function indicated that a $4 \mathrm{n}$ reaction had been observed.

However, one of the problems involved in claiming discovery of a new element only by observation of its SF activity is the difficulty of proving the atomic number of the fissioning species since the fission process effectively destroys this. Consequently, in an effort to confirm the atomic number of this SF activity, gas chromatographic separations were performed over the years $1966-69$ by Zvara et al. [33]. They based their separation on the actinide hypothesis which predicted that element 104 should be eka-hafnium and tried to show that the 0.3 -s SF activity had a volatile chloride and 
would follow the volatile $\mathrm{HfCl}_{4}$ while the heavy actinides would not. These experiments used isothermal chromatography $\left(250\right.$ or $300{ }^{\circ} \mathrm{C}$ and were designed for a half-life of $0.3 \mathrm{~s}$. (Possible contamination from $\mathrm{Pu}$ was recognized as a potential problem.) A total of 14 SFs were recorded in mica detectors in this series of experiments and attributed to $260_{104}$. The authors stated that the fission track distribution was consistent with a 0.3-s half-life and "shows positively that the effect was not caused to an appreciable extent by the decay of nuclides undergoing SF with half-lives of $0.014 \mathrm{~s}$ and $3.7 \mathrm{s"}$. Later experiments reported by Zvara et al. in 19691970 [34] were in agreement with the previous ones and they accepted $0.5 \mathrm{~s}$ as the correct value of the SF half-life. (In 1969, Druin and coworkers determined the halflife to be $0.1 \mathrm{~s}$ and subsequently it was dropped to $0.02 \mathrm{~s}$, much too short to have been observed in this chemistry!) However, the use of gas chromatography has since become a valuable tool for studying chemical properties of the transactinide elements [23, 24].

Ghiorso et al. [35] in 1969 at the HILAC at LBL were unable to confirm existence of a 0.3 -s isotope of ${ }^{260} 104$ using the reactions ${ }^{246} \mathrm{Cm}\left({ }^{18} \mathrm{O}, 4 \mathrm{n}\right)$ and ${ }^{248} \mathrm{Cm}\left({ }^{16} \mathrm{O}, 4 \mathrm{n}\right)$. However, they chose to try to positively identify the $\mathrm{Z}$ and $\mathrm{A}$ of new $\alpha$-emitting isotopes of 104 using the method of $\alpha$ - $\alpha$ correlations in which the $\alpha$-decay of known recoiling daughter activities is correlated with that of the parent. A new instrument called the Vertical Wheel (VW) was developed for this purpose. The VW and the following reactions were used to positively identify two new isotopes of element 104 [36]:

$$
\begin{gathered}
{ }^{249} \mathrm{Cf}\left({ }^{12} \mathrm{C}, 4 \mathrm{n}\right){ }^{257} 104(\mathrm{Rf})(\sigma \sim 0.01 \mu b) \stackrel{\alpha . \sim 4.5 \mathrm{~s}}{\longrightarrow}{ }^{253} \text { No }(1.7 \mathrm{~m}) \\
{ }^{249} \mathrm{Cf}\left({ }^{13} \mathrm{C}, 3 \mathrm{n}\right){ }^{259}{ }_{104(\mathrm{Rf})(\sigma \sim 0.01 \mu b) \stackrel{\alpha / \mathrm{SF} ? \sim 3 \mathrm{~s}}{\longrightarrow}}>{ }^{255} \text { No }(3.1 \mathrm{~m}) \\
{ }^{248} \mathrm{Cm}\left({ }^{16} \mathrm{O}, 5 \mathrm{n}\right){ }^{259}{ }_{104(\mathrm{Rf})}
\end{gathered}
$$

In 1973, an independent group of American scientists led by C. L. Bemis, Jr. [37] at Oak Ridge National Laboratory confirmed the identification of 257104 using the same reaction as did Ghiorso et al. They identified the characteristic $K \mathrm{X}$-rays of element 102 in coincidence with the $\alpha$-particles from decay of the 4.5-s 257104 .

The Berkeley group chose Rutherfordium, symbol Rf, for element 104 while the Dubna group proposed Kurchatovium, symbol Ku. Rutherfordium (Rf) was accepted by the American Chemical Society (ACS) in 1994 for use in their journals.

\subsubsection{Hahnium (Element 105)}

Flerov et al. reported in 1970 [38] that they had produced a 0.1- to 0.3-s $\alpha$-emitter at the $300-\mathrm{cm}$ Cyclotron at Dubna in the following reaction:

$$
{ }^{243} \mathrm{Am}\left({ }^{22} \mathrm{Ne}, 5 \mathrm{n}\right){ }^{260} 105(\sigma \sim 0.1 \mathrm{nb}) \stackrel{9.7-\mathrm{MeV} \alpha \cdot 0.1-3 \mathrm{~s}}{\longrightarrow}
$$

The atoms recoiling out of the target were transported via $\mathrm{He}$ jet through an annular detector to a metal collector wheel and correlations with $\alpha$-daughter activities were looked for. (A new apparatus was used for this purpose.) Unfortunately, the quality of the alpha data is poor and even in 1971 papers by Druin et al. [39] shows no close 
resemblance to the much better data published about the same time or even earlier by Ghiorso et al. [40]. Zvara et al. again reported (unpublished results in 1970 and 1973) using gas chromatography to attribute a 1.8-s SF activity reported earlier by Flerov $e$ al. to element 105 , but from these results it is not possible to conclude that the observed SFs are from a homolog of $\mathrm{Nb}$ and $\mathrm{Ta}$, and hence, to element 105 .

In papers published in 1970 [40] and 1971 [41], Ghiorso et al. presented convincing evidence that isotopes of element 105 were produced and positively identified using the $\alpha-\alpha$ correlation technique with the VW in the following reactions performed at the HILAC at Berkeley:

$$
\begin{gathered}
{ }^{249} \mathrm{Cf}\left({ }^{15} \mathrm{~N}, 4 \mathrm{n}\right){ }^{260} 105(\mathrm{Ha})(\sigma \sim 0.01 \mu \mathrm{b}) 9.1-\mathrm{MeV} \alpha, 1.6 \mathrm{~s} \\
>
\end{gathered}
$$

These results were later confirmed by Bemis et al. [42], using an $L$ X-ray-alpha coincidence technique.

The Berkeley group chose the name Hahnium, $\mathrm{Ha}$, for element 105 and the Dubna group proposed Nielsbohrium, Ns. Again, Hahnium (Ha) was approved by the ACS.

In 1974, an ad hoc committee of neutral experts was set up by the International Union of Pure and Applied Chemistry (IUPAC) and the International Union of Pure and Applied Physics (IUPAP) which included three members each from the USSR, the USA, and three neutral countries. Their charter was "to consider the claims of priority of discovery of elements 104 and 105 and to urge the laboratories at Berkeley and Dubna to exchange representatives and in their presence to repeat the experiments regarding these elements." However, these attempts proved fruitless and the committee was disbanded. However, the American members decided to prepare and later publish an article giving the history and an analysis of the discovery of elements 104 and 105 with a complete review of the experimental studies carried out at both laboratories between 1960 to 1977, including a complete bibliography [31].

\subsubsection{Seaborgium (Element 106)}

Element 106 was produced by a Berkeley-Livermore group led by A. Ghiorso [43] using the following reaction and the VW to measure $\alpha-\alpha$ correlations with its known $\alpha$-emitting daughter, $3.0-\mathrm{s}{ }^{259} \mathrm{Rf}$ :

$$
{ }^{249} \mathrm{Cf}\left({ }^{18} \mathrm{O}, 4 \mathrm{n}\right){ }^{263} 106(\sigma \sim 0.6 \mathrm{nb}) \stackrel{\alpha .0 .9 \mathrm{~s}}{\longrightarrow}{ }^{259} \operatorname{Rf} \underline{\alpha .3 .0 \mathrm{~s}}>
$$

Recently, Gregorich et al. [44] confirmed the original experiment using a different detection system and the 88-Inch Cyclotron at Lawrence Berkeley National Laboratory. The name Seaborgium, symbol Sg, was proposed on behalf of the discovery group by E. K. Hulet [45] at the April, 1994 National meeting of the American Chemical Society 
(ACS). A short time later, Seaborgium (Sg) was approved by the ACS for use in its journals.

\subsection{NIELSBOHRIUM(ELEMENT 107) THROUGH MEITNERIUM (ELEMENT 109)}

Elements 101 through 106 were first produced using compound nucleus reactions between actinide targets and light heavy ions in what might be called "hot fusion" reactions because of the rather high excitation energy of the compound nucleus which is produced. This increases the tendency for the compound system to fission promptly, which results in lower and lower cross sections for the desired (xn) reactions. as the Z of the compound nucleus is increased. It was suggested by Oganessian of Dubna that "cold fusion" reactions between target nuclides near the doubly magic ${ }^{208} \mathrm{~Pb} \quad(\mathrm{Z}=82$, $\mathrm{N}=152$ ) might be used with appropriate neutron-rich heavy ion projectiles in the region around $\mathrm{Fe}(26)$ to give a relatively "cold" compound system which might emit only 1 or 2 neutrons and have a much lower prompt fission cross section. A group at the Gesellschaft für Schwerionenforschung (GSI) in Darmstadt, Germany led by P. Armbruster [46] exploited this type of reaction to produce the new elements 107, 108, and 109. Their recently constructed Separator for Heavy Ion reaction Products (SHIP) was used to separate the resulting reaction products from the beam projectiles and identify the new element isotopes by measuring their decay chains to known daughter, granddaughter, etc., nuclides.

In this way, positive identification of the new element isotopes could be made on the basis of the observation of only a few atoms. The new elements 107, 108, and 109 were first identified $[47,48,49]$ in the following reactions at the UNILAC at GSI, Darmstadt:

$$
\begin{aligned}
& { }^{209} \mathrm{Bi}\left({ }^{54} \mathrm{Cr}, \mathrm{n}\right){ }^{262} 107(\sigma-0.2 \mathrm{nb}) \frac{10.38-\mathrm{MeV} \alpha,-4.7 \mathrm{~ms}}{2}>\text { known decay chain } \\
& { }^{209} \mathrm{~Pb}\left(^{58} \mathrm{Fe}, \mathrm{n}\right){ }^{265} 108(\sigma \sim 0.02 \mathrm{nb}) \stackrel{10.36-\mathrm{MeV} \alpha,-1.8 \mathrm{~ms}}{>}>\text { known decay chain } \\
& { }^{209} \mathrm{Bi}\left({ }^{58} \mathrm{Fe}, \mathrm{n}\right){ }^{266} 109(\sigma \sim 0.015 \mathrm{nb}) \stackrel{11.1-\mathrm{MeV} \alpha,-3.5 \mathrm{~ms}}{\longrightarrow}>\text { known decay chain }
\end{aligned}
$$

The name Nielsbohrium (Ns) was proposed by the GSI group in recognition of the suggestion of use of the "cold fusion" reaction and experiments done on element 107 by the Russian group at Dubna who had earlier suggested this name for element 105 . The name Hassium (Hs) was suggested in honor of the state of Hesse where the experiments had been performed, and Meitnerium (Mt) was proposed in honor of the famous woman scientist Lise Meitner who was instrumental in the discovery of nuclear fission and in explaining and interpreting this new phenomenon.

These names were also approved by the ACS in 1994 for use in their journals.

\subsection{ELEMENTS 110 THROUGH 112}

As the cross sections for the production of still heavier elements and the expected halflives dropped, it became necessary to improve the efficiency and discrimination of 
existing on-line separator systems. Thus, considerable time elapsed between the discovery of element 109 and the reports of the discovery of element 110.

\subsubsection{Element 110}

The first report of possible evidence for the production of element 110 at the SUPERHILAC at Berkeley in 1991 was made by A. Ghiorso et al. in 1994 and 1995 [50], based on the partial decay chain of one event. The newly improved gas-filled Small Angle Separator SYstem (SASSY-2) was used to separate and identify products from the following reaction:

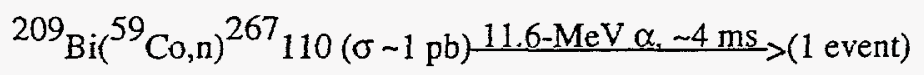

S. Hofmann et al. [51], using the SHIP whose efficiency and detection system had been greatly improved, performed experiments during November and December of 1994 at the UNILAC, GSI, Germany and in 1995 reported identifying two new isotopes of element 110 in the following reactions:

$$
\begin{aligned}
& { }^{208} \mathrm{~Pb}\left({ }^{62} \mathrm{Ni}, \mathrm{n}\right){ }^{269} 110(\sigma \sim 4 \mathrm{pb}) \stackrel{11.1-\mathrm{MeV} \alpha .0 .17 \mathrm{~ms}}{\longrightarrow} \text { (3 events) } \\
& { }^{208} \mathrm{~Pb}\left({ }^{64} \mathrm{Ni}, \mathrm{n}\right){ }^{271} 110(\sigma-15 \mathrm{pb}) \stackrel{10.7-\mathrm{MeV} \alpha .1 .1 \mathrm{~ms}}{\longrightarrow} \text { (9 events) }
\end{aligned}
$$

A combined Dubna-Lawrence Livermore National Laboratory (LLNL) team led by Yu. A. Lazarev performed experiments at the Dubna Cyclotron using the Dubna gas-filled recoil separator during September to December, 1994 and in 1995 reported [52] evidence for one event of element 110 produced in the following "hot fusion" reaction:

$$
{ }^{244} \mathrm{Pu}\left({ }^{34} \mathrm{~S}, 5 \mathrm{n}\right){ }^{273} 110(\sigma \sim 0.4 \mathrm{pb}) \stackrel{11.4-\mathrm{MeV} \alpha .0 .3 \mathrm{~ms}}{\longrightarrow}>(1 \text { event })
$$

Different isotopes of element 110 were produced in all of these reactions, so none can be considered confirmation of the others; however, the half-lives and cross sections all appear to be reasonable. Clearly, the group of S. Hofmann has more convincing data for their discoveries of 269110 and 271110 . No name has as yet been proposed for element 110 .

\subsubsection{Element 111}

The same group of S. Hofmann et al. also reported [53] identification of three atoms of element 111 using the SHIP at GSI with rather complete supporting decay chains formed in the following reaction:

$$
{ }^{209} \mathrm{Bi}\left({ }^{64} \mathrm{Ni}, \mathrm{n}\right){ }^{272} 111(\sigma \sim 3.5 \mathrm{pb}) \stackrel{10.8-\mathrm{MeV} \alpha .1 .5 \mathrm{~ms}}{\longrightarrow} \text { ( } 3 \text { events) }
$$

No name has yet been proposed for this element. 


\subsubsection{Element 112}

Additional experiments carried out by S. Hofmann et al. in February, 1996 [54] at GSI using SHIP resulted in the identification of two decay chains of element 112 produced in the following reaction:

$$
\left.{ }^{208}{ }_{\mathrm{Pb}(}{ }^{70} \mathrm{Zn,n}\right){ }^{277} 112(\sigma-3.5 \mathrm{pb}) \stackrel{11.45,11.65-\mathrm{MeV} \alpha, 0.3 \mathrm{~ms}}{>}>\text { (2 events) }
$$

Again, no name has yet been proposed for this element.

\subsection{HEAVY ELEMENT NAMING}

In 1987, the IUPAP and the IUPAC appointed a new Transfermium Working Group (TWG) to assign credit for discovery of the elements heavier than fermium (element 100) even though names for the elements through 103 had been approved previously by IUPAC. Their report assigning credit for discovery of elements 101 through 109 was published in 1993 [55] and proved to be rather controversial in the cases of elements 102,104, and 105. Subsequent to this, the IUPAC Commission on Nomenclature of Inorganic Chemistry (CNIC), A. M. Sargeson, Chair, presented [56] a rather different list of names for elements 103 through 109 to the IUPAC Council than had been proposed by the acknowledged discoverers; notable were the proposed names for elements 106 through 108 about which there was no controversy. Rutherfordium (Rf) was assigned to element 106 and seaborgium for element 106 was thrown out because of an ex post facto ruling that an element could not be named after a living person and Glenn T. Seaborg is still alive. Bohrium (Bh) was proposed for element 107 instead of Nielsbohrium (Ns); hahnium was moved from element 105 to element 108, replacing the discoverers proposed name of Hassium (Hs) for element 108. Only Lawrencium ( $\mathrm{Lr}$ ) for element 103 (previously approved by IUPAC) and Meitnerium (Mt) for element 109 were accepted! Dubnium (Db) for element 104 and Joliotium (J) for element 105 replaced Rutherfordium (104) and Hahnium (105) which have been in common usage for these elements for some 25 years. This change, together with shifting Rutherfordium to element 106 and Hahnium to element 108, has created a chaotic situation in heavy element nomenclature, especially since many studies on the chemical properties of these elements have been published using the other names. Because of the controversy surrounding these new IUPAC names, IUPAC decided to return them to "provisional" status and the CNIC invited comments on them until May 31,1996 and they are currently being reconsidered.

\section{Future}

The production of elements $267,269_{110}$ and $272_{111}$ in "cold fusion" reactions with cross sections of a few $\mathrm{pb}$ and of $271_{110}$ with a cross section of $-15 \mathrm{pb}$, the estimate of $\sim 0.4 \mathrm{pb}$ for the "hot fusion" reaction to produce 273110 , and the cross section of $\sim 1$ $\mathrm{pb}$ for the cold fusion reaction to produce $277_{112}$ make it appear feasible to produce and detect elements 113 and 114 as well. Somewhat lower cross sections are estimated 
for the cold fusion reactions of $70_{\mathrm{Zn}}$ or ${ }^{76} \mathrm{Ge}$ with $\mathrm{Pb}$ or $\mathrm{Bi}$ to produce elements 113 and 114 , but these should be within the reach of the SHIP group. A more efficient gas-filled separator with an opening angle of $12.2^{\circ}$ for compound-nucleus recoils compared to $3.6^{\circ}$ for SHIP has been proposed by K. Gregorich et al. [57] at Lawrence Berkeley National Laboratory; this Berkeley Gas-filled Separator (BGS) should provide access to nuclides with still lower production cross sections, and would be particulariy advantageous for asymmetric reactions which have a broad angular distribution, including that resulting from scattering of recoils in the target itself. Thus thicker targets can be used and it appears promising to use the BGS with its higher sensitivity to reinvestigate the following more asymmetric "hot fusion" reactions:

$$
{ }^{244} \mathrm{Pu}\left({ }^{48} \mathrm{Ca}, 4 \mathrm{n}\right)^{288} 114
$$

$$
{ }^{248} \mathrm{Cm}\left({ }^{48} \mathrm{Ca}, 4 \mathrm{n}\right){ }^{292} 116 \text { (earlier limit of } 200 \mathrm{pb} \text { set for half-lives }>1 \mathrm{~ms} \text { ) }
$$

With the expected efficiency of the BGS, a cross section of $1 \mathrm{pb}$ should result in the detection of nearly two events per week. Thus it now appears possible to reach the long sought superheavy elements in the region of the spherical $Z=114$ shell, but with fewer neutrons than the $\mathrm{N}=184$ spherical shell.

\section{Acknowledgements}

The author wishes to thank her colleague and friend Diana $M$. Lee for her invaluable help in producing the figures and her support during preparation of this paper.

Work performed under the auspices of the U.S. Department of Energy by the Lawrence Livermore National Laboratory under Contract W-7405-Eng-48.

\section{References}

1. Fermi, E. (1934) Possible Production of Elements of Atomic Number Higher than 92, Nature 133, 898.

2. Noddack, I. (1934) Uber das Element 93, Angew. Chem. 47, 653-655.

3. Hahn, O., Meitner, L., Strassmann, F. (1936) Elemente jenseiťs Unan. Berichte 69, 905-919.

4. Curie, I., Savitch, P. (1938) Sur la nature du radioelement de periode 3.5 heures forme dans furarium irradie par les neutrons, Compte Rendus 206, 1643-1644.

5. Hahr. O., Strassmann, F. (1939). Über den Nachweis und das Verhalten der bei der Bestrahlung des Urans mittels Neutronen entstehenden Erdalkalimetalle, Naturwissenschofien 27, 11-15.

6: Metiner, L. and Frisch, O.R (1939) Disintegration of Uranium by Neutrons: A New Type of Nuclear Reaction, Nature (Letters) 143, 239-240.

7. Frisch, O. R. (1939) Physical Evidence for the Division of Heavy Nuclei under Neutron Bombartiment, Nanure (Letters) 143, 276.

8. Mcilillan, E. M. and Abelson. P. H. (1940) Radicactive Element 93 Phys. Rev. 57, 1185-1186.

9. Seaborg. G. T., Mc.Millan, E. M., Kennedy, J. W., and Wahl, A. C. (1946) Radioactive Element 94 from Deuterons on Uranium, Phys. Rev. 69, 366-367.

10. Seaborg. G. T., Wahl., A. C., and Kennedy, J. W. (1946) Radioaceive Element 94 from Deuterons on Uranium, Phys. Rev. 69, 367. 
11. Kennedy, J. W., Seaborg, G. T., Segre, E., and Wahl, A. C. (1946) Properties of 94 (239), Phys. Rev. 70, 555-556.

12. Seaborg, G. T. (1995) Transuranium Elements: The Synthetic Actinides, Radiochimica Acta 70/71, 69-90.

13. Seaborg, G. T. (1945) The Chemical and Radioactive Properties of the Heavy Elements, Chem \& Eng. News 23, 2190-2193.

14. Ghiorso, A., James, R. A., Morgan, L. O., and Seaborg, G. T. (1950) Preparation of Transplutonium Isotopes by Neutron Irradiation, Phys. Rev. 78, 472.

15. Thompson, S. G., Ghiorso, A., and Seaborg, G. T. (1950) Element 97, Phys. Rev. 77, 838-839.

16. Thompson, S. G., Street, K., Jr., Ghiorso, A., and Seaborg, G. T. (1950) Element 98, Phys. Rev. 78, 298-299.

17. Ghiorso, A., Thompson, S. G., Higgins, G. H., Seahorg, G. T., Studier, M. H., Fields, P. R., Fried, S. M., Diamond, H., Mech, J. F., Pyle, G. L., Huizenga, J. R., Hirsch, A., Manning, W. M., Browne, C. I., Smith, H. L., and Spence, R. W. (1955) New Elements Einsteinium and Fermium, Atomic Numbers 99 and 100, Phys. Rev. 99, 1048-1049.

18. Ghiorso, A., Harvey, B. G., Choppin, G. R., Thompson, S., and Seaborg, G. T. (1955) New Element Mendelevium, Atomic Number 101, Phys. Rev. 98, 1518-1519.

19. Fields, P. R., Friedman, A. M., Milsted, J., Atterling, H., Forsling, W., Holm, L. W., and Astrom, B. (1957) Production of the New Element 102, Phys. Rev. 107, 1460-1462.

20. Ghiorso, A., Sikkeland, T., Walton, J. R., and Seaborg, G. T. (1958) Attempts to Confirm the Existence of the 10-Minute isotope of 102, Phys. Rev. Lett. 1, 17-18.

21. Flerov, G. N., Polikanov, S. M., Karamian, A. S., Pasiuk, A. S., Parfanovich, D. M., Tarantin, N. I., Karnaukhov, V. A., Druin. V. A., Volkov, V. V., Semchinova, A. M., Oganessian, Yu. Ts., Khalizev, V. I., and Khlevnikov, G. I. (1958) Experiments to Produce Element 102 (Engl. trans.), Sov. Phys. Dokl. 3, 546-548.

22. Silva, R. J., Sikkeland, T., Nurmia, M., and Ghiorso, A. (1969) Determination of the No(II)-No(III) Potential from Tracer experiments, J. Inor. Nucl. Chem. 31, 3405-3509.

23. Hoffman, Darieane C., (1994) The Heaviest Elements, Chem. \& Eng. News, May 2, 1994, 24-34

24. Hoffman, Darieane C., (1996) Chemistry of the Heaviest Elements, Radiochimica Acta 72, 1-6.

25. Ghiorso, A., Sikkeland, T., Walton, J. R., and Seaborg, G. T. (1958) Element 102, Phys. Rev. Lent. 1, $17-18$

26. Flerov, G. N. (1958) Heavy Ion Reactions, Proc. Second United Nations Internatl. Conf. Peacefil Uses of Atomic Energy 14, 151-157.

27. Donets, E. D., Schegolev, V. A., and Ermakov, V. A. (1964) Synthesis of Element 102 of Mass Number 256 (Engl. trans.) Sov. J. At. Energy 16, 233-245.

28. Ghiorso, A., Sikkeland, T. Larsh, A. E., and Latimer, R. M. (1961) New Element Lawrencium. Atomic Number 103. Phys. Rev. Lett. 6, 473-475.

29. Donets, E. D., Schegolev, V. A., and Ermakov, V. A. (1965) Synthesis of the Isotope of Element 103 (Lawrencium) with Mass Number 256 (Engl. trans.) Sov. J. At. Energy 19, 995-999.

30. Silva, R. J., Sikkeland, T., Nurmia, M., and Ghiorso, A. (1970) Tracer Chemical Studies of Lawrencium, Inorg. Nucl. Chem. Lett. 6, 733-739.

31. Hyde, E. K., Hoffman, D. C., and Keller, Jr., O. L. (1987) A History and Analysis of the Discovery of Elements 104 and 105, Radiochimica Acta 41, 57-102.

32. Flerov, G. N., Oganessian, Yu. Ts., Lobanov, Yu. V., Kuznetsov, V. I., Druin. V. A., Perelygin. V. P.. Gavrilov, K. A.. Tretyakova. S. P., and Plocko, V. M. (1964) Synthesis and Physical Identification of 
the Isotope of Element 104 with Mass Number 260, Atomnaya Energ. 17, 310; Phys. Lett. 13, 73.

33. Zvara, I. et al. (1966) Chemical Properties of Element 104, At. Energ. 21, 83-84; ; Sov. At. Energy 21 , 709-710; (1969) Experiments on the Chemistry of Elernent 104-Kurchatovium, Soviet Radiochem. 11, 153-181.

34. Zvara, I. et al. (1970) J. Inorg. Nucl. Chem. 32(6), 1885-94.

35. Ghiorso, A., Nurmia, M., and Harris, J. $(1968,1969)$ University of California Radiation Laboratory Report No. UCRL 1886 7, p. 61 and UCRL-18714 (unpublished).

36. Ghiorso, A., Nurmia, M., Harris, J., Eskola, K., and Eskola, P. (1969) Positive Identification of Two Alpha-Particle-Emitting Isotopes of Element 104, Phys. Rev. Lett. 22, 1317.

37. Bemis, Jr., C. E., Silva, R. J., Hensley, D. C., Keller, Jr., O. L., Tarrant, J. R., Hunt, L. D., Dittner, P. F., Hahn, R. L., and Goodman, C. D. (1973) X-Ray Identification of Element 104, Phys. Rey. Lett. 31 , 647-650.

38. Flerov, G. N., Oganessian, Yu. Ts., Lobanov, Yu. V., Lazarev, Yu. A., Tretyakova, S. P., Kolesov, I. V., and Plotko, V. M. (1971) On the Synthesis of Element 105, Nucl. Phys. A160, 181-192.

39. Druin, V. A., Demin, A. G., Kharitonov, Yu. P., Akapiev, G. N., Rudd, V. I., Sung-Ching-Yang, G. Y., Chelnokov, L. P., and Gavrilov, K. A. (1971) Sov. J. Nucl. Phys. 13, 139-141; Yad. Fiz 13, 251-255.

40. Ghiorso, A., Nurmia, M., Eskola, K., Harris, J., and Eskola, P. (1970) New Element Hahnium, A.tomic Number 105, Phys. Rev. Lett. 24, 1498-1503.

41. Ghiorso, A., Nurmia, M., Eskola, K., and Eskola, P. (1971) Two New Alpha-Particle-Emitting Isotopes of Element $105,{ }^{261} \mathrm{Ha}$ and ${ }^{262} \mathrm{HaPhys}$. Rev. C4, 1850-1855.

42. Bemis, Jr., C. E., Dituner, P. F., Silva, R. J., Hahn, R. L., Tarrant, J. R., Hunt. L. D., and Hensiey, D. C. (1977) Production, $L \mathrm{x}$-ray identification and decay of the nuclide ${ }^{260} 105$, Phys. Rev. $C$ 16, 1146-1157.

43. A. Ghiorso, Nitschke, J. M., Alonso, J. R., Alonso, C. T., Nurmia, M., Seaborg, G. T., Hulet, E. K., and Lougheed, R. W. (1974) Element 106, Phys. Rev. Letr. 33, 1490-1493.

44. Gregorich, K. E., Lane, M. R.. Mohar, M. F., Lee, D. M., Kacher, C. D., Sylwester, E. R., and Hoffman, D. C. (1994) First Confimation of the Discovery of Element 106, Phys. Rev. Lett. 72. 1423-1426.

45. Hulet, E. K., (1994) ACS Award Symposium, April, 1994 ACS Meeting, San Diego, CA (unpublished).

46. Armbruster, P. (1985) On the Production of Heavy Elements by Cold Fusion: The Elements 106 to 109, Ann. Rev. Nucl. Part. Sci. 35, 135-194.

47. G. Münzenberg et al. (1981) Element 107, Z. Phys. A300, 107.

48. G. Münzenberg et al. (1984) Element 109, Z Phys. A309, 89; A315, 145.

49. G. Münzenberg et al. (1984) Element 108, Z. Phys. A317, 235.

50. Ghiorso, A. et al. (1994) Evidence for the Synthesis of Element ${ }^{267} 110$ produced by the ${ }^{59} \mathrm{Co}+{ }^{209} \mathrm{Bi}$ reaction, Fifth International Conf. on Nucleus-Nucleus Collisions, Taumina. Italy; May: 1994, Nucl. Phys. A583, 861-865; (1995) Evidence for the possible synthesis of element 110 produced by the ${ }^{59} \mathrm{Co}+{ }^{209} \mathrm{Bi}$ reaction, Phys. Rev. C (Rapid Communications) 51, R2293-R2297.

5I. Hofmann, S., Ninov, V., Hessberger, F. P., Armbruster, P. Folger, H., Munzenberg, G., Schort. H. J. Popeko, A. G., Yeremin, A. V., Andreyev, A. N., Saro, S., Janik, R., Leino, M. (1995) Production and decay of 269110 , Z. Phys. A350, 277-280.

52. Lazarev, Yu. A. et al. (1996) Alpha Decay of 273110 : Shell Closure at $N=162$. Phys. Rev: $C$ (In press).

53. Hofmann, S. et al. (1995) The new element 111, Z Phys. A350. 281-282.

54. Hofmann, S. et al. (1996) The new element 112. Z. Phys.A (Short Note) 354, 229-230. 
55. Wilkinson, D. H., Wapstra, A. H., Ulehia, I., Barber, R. C., Greenwood, N. N., Hrynkiewicz, A., Jeannin, Y.P., Lefort, M., and Sakai, M. (1993) Discovery of the Transfermium Elements, Pure Appl. Chem. 65, 1757-1814.

56. IUPAC Commission on Nomenclature of Inorganic Chemistry, Sargeson, A. M., Chair (1994) Names and Symbols of Transfermium Elements (IUPAC Recommendations 1994) Pure Appl. Chem. 66, 2419-2421.

57. Gregorich, K., private communication, 1996. 


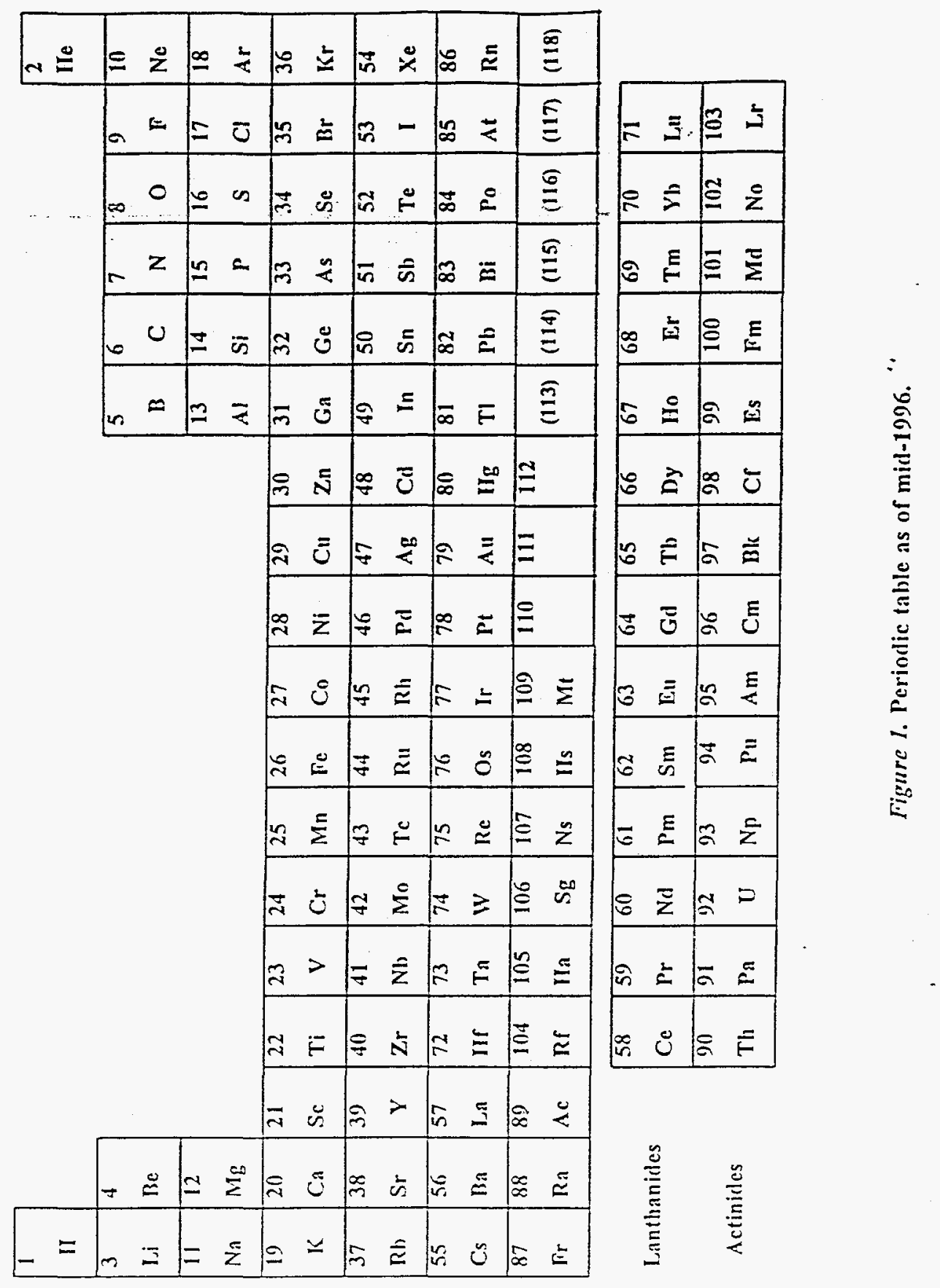




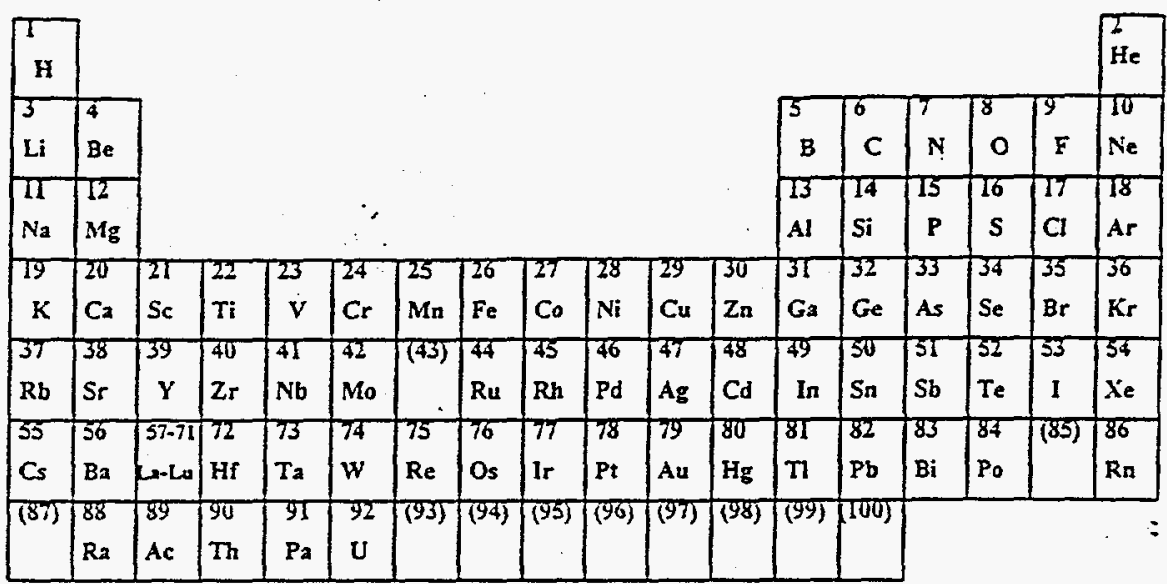

\begin{tabular}{|c|c|c|c|c|c|c|c|c|c|c|c|c|c|c|}
\hline 57 & 58 & 59 & 60 & $(61)$ & 62 & 63 & 64 & 65 & 66 & 67 & 68 & 69 & 70 & 71 \\
\hline La & $\mathrm{Ce}$ & $\mathrm{Pr}$ & Nd & & $\mathrm{Sm}$ & Ev & Gd & Tb & Dy & $\mathrm{Ho}_{0}$ & Er & $\mathrm{Tm}$ & Yb & Lu \\
\hline
\end{tabular}

Figure 2. Periodic table before world war II

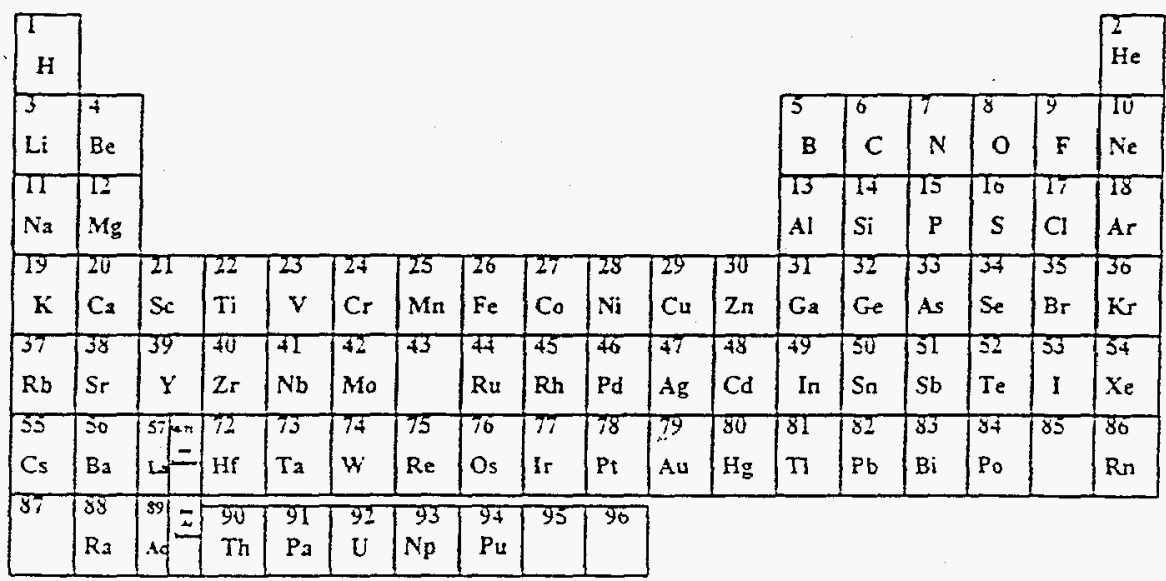

\begin{tabular}{|c|c|c|c|c|c|c|c|c|c|c|c|c|c|c|c|}
\hline Lanthanides & $\begin{array}{l}57 \\
L_{2}\end{array}$ & {$\left[\begin{array}{l}53 \\
\mathrm{Ce}\end{array}\right.$} & $\begin{array}{l}39 \\
\mathrm{Pr}\end{array}$ & $\begin{array}{l}00 \\
\mathrm{Nd}\end{array}$ & 01 & $\begin{array}{c}02 \\
5 \mathrm{~m}\end{array}$ & $\begin{array}{l}63 \\
E_{u}\end{array}$ & $\begin{array}{l}64 \\
\mathrm{Gd}\end{array}$ & $\begin{array}{l}65 \\
\mathrm{~Tb}\end{array}$ & $\begin{array}{l}00 \\
D y\end{array}$ & $\begin{array}{l}67 \\
\mathrm{Ho}\end{array}$ & $\begin{array}{l}08 \\
\text { Er }\end{array}$ & $\begin{array}{l}09 \\
\operatorname{Tm}\end{array}$ & $\begin{array}{l}70 \\
16\end{array}$ & $\begin{array}{l}\pi \\
\mathrm{Lu}\end{array}$ \\
\hline Actinides & $\begin{array}{l}39 \\
\text { Ac }\end{array}$ & $\begin{array}{l}90 \\
T h\end{array}$ & $\begin{array}{l}91 \\
\mathrm{~Pa}\end{array}$ & $\begin{array}{l}\text { प्र2 } \\
\text { U }\end{array}$ & $\begin{array}{l}93 \\
N_{p}\end{array}$ & $\begin{array}{l}\text { प्र4 } \\
P_{4}\end{array}$ & 95 & 96 & & & & & & & \\
\hline
\end{tabular}

Figure 3. Representation of Seaborg's 1945 periodic table showing an actinide series. 


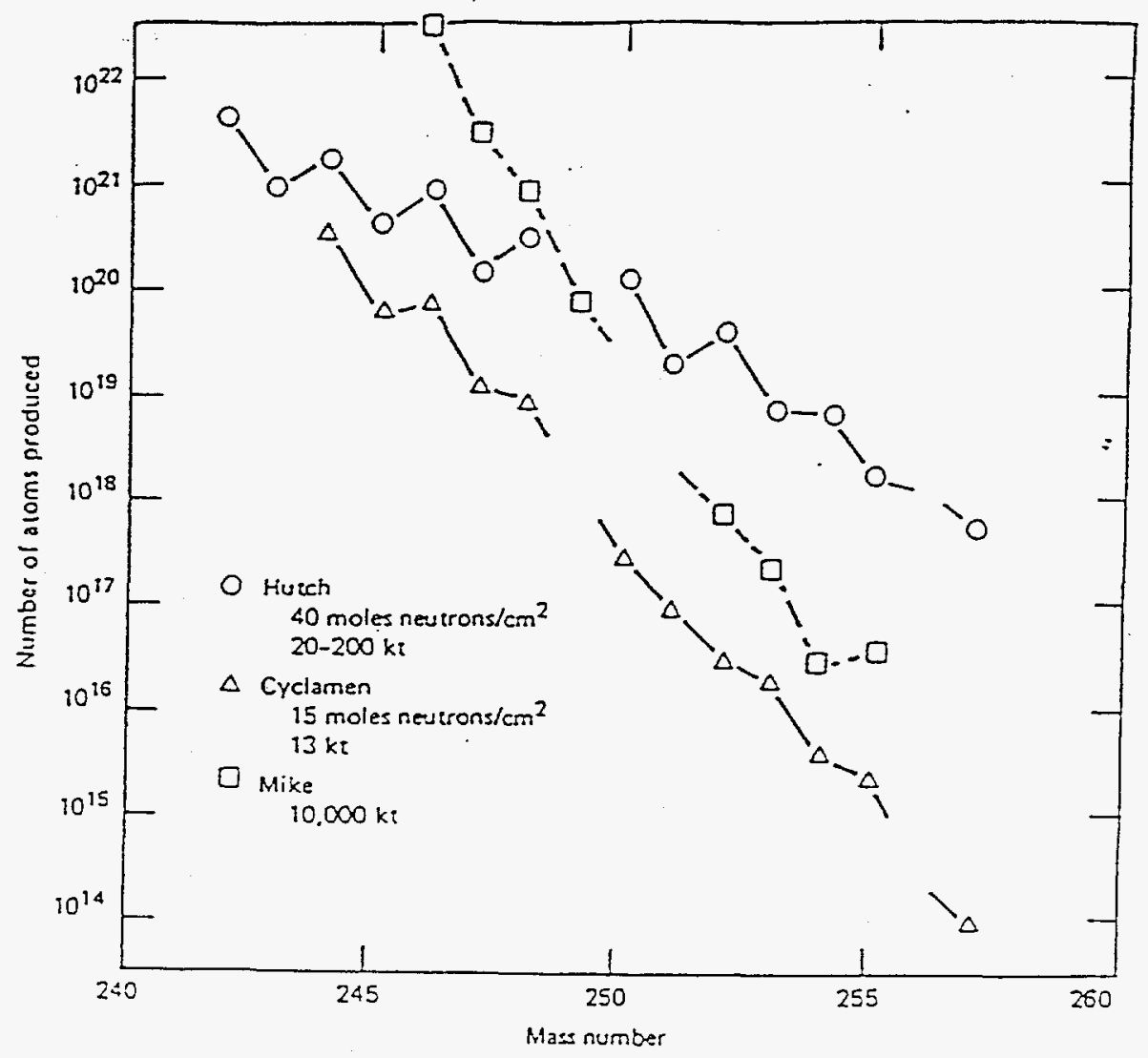

Figure 4. Production yields for different tests. 


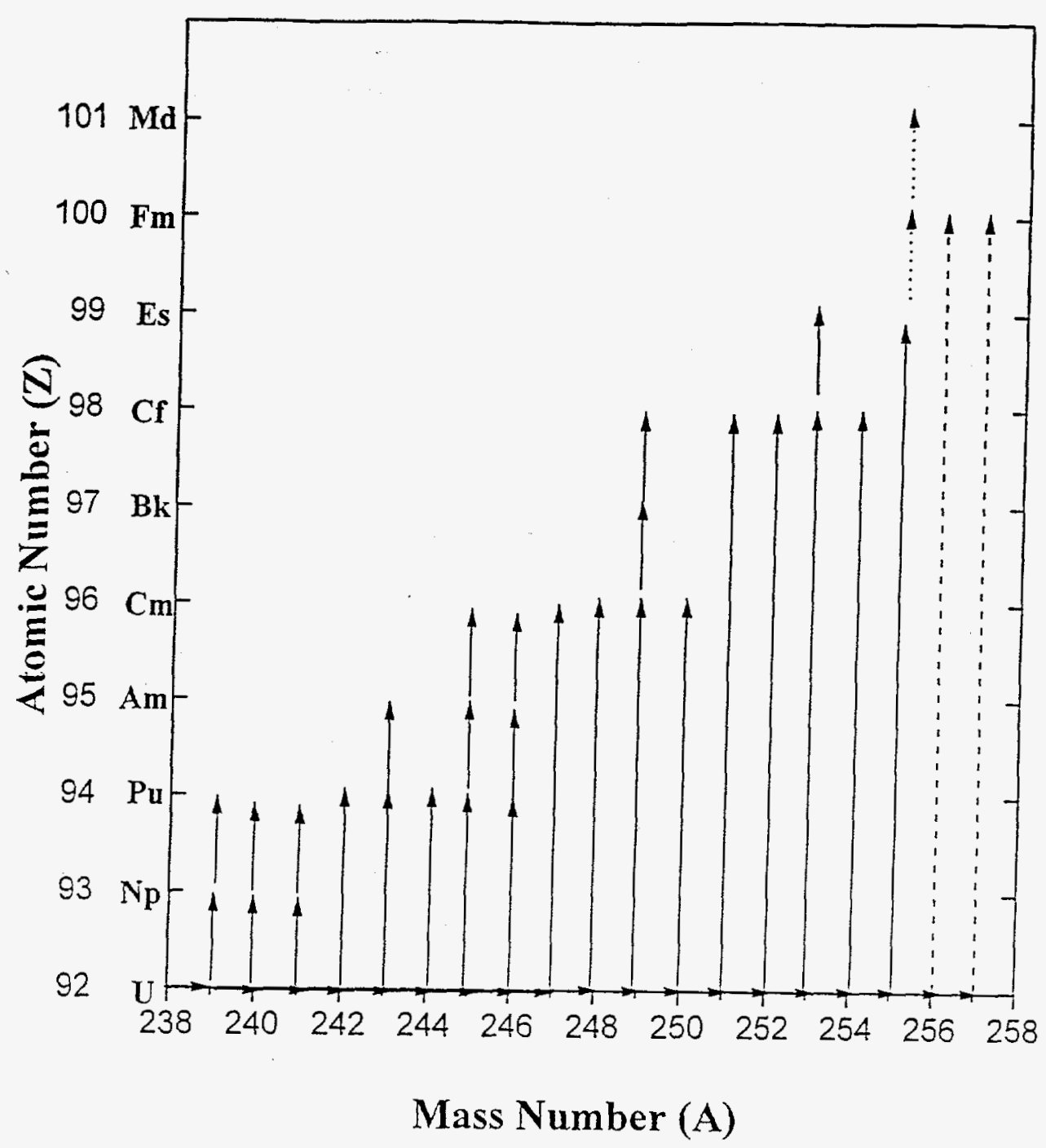

Figure 5. Production of uranium isotopes in the "Mike" thermonuclear device, and their subsequent decay to beta-stable nuclei. 


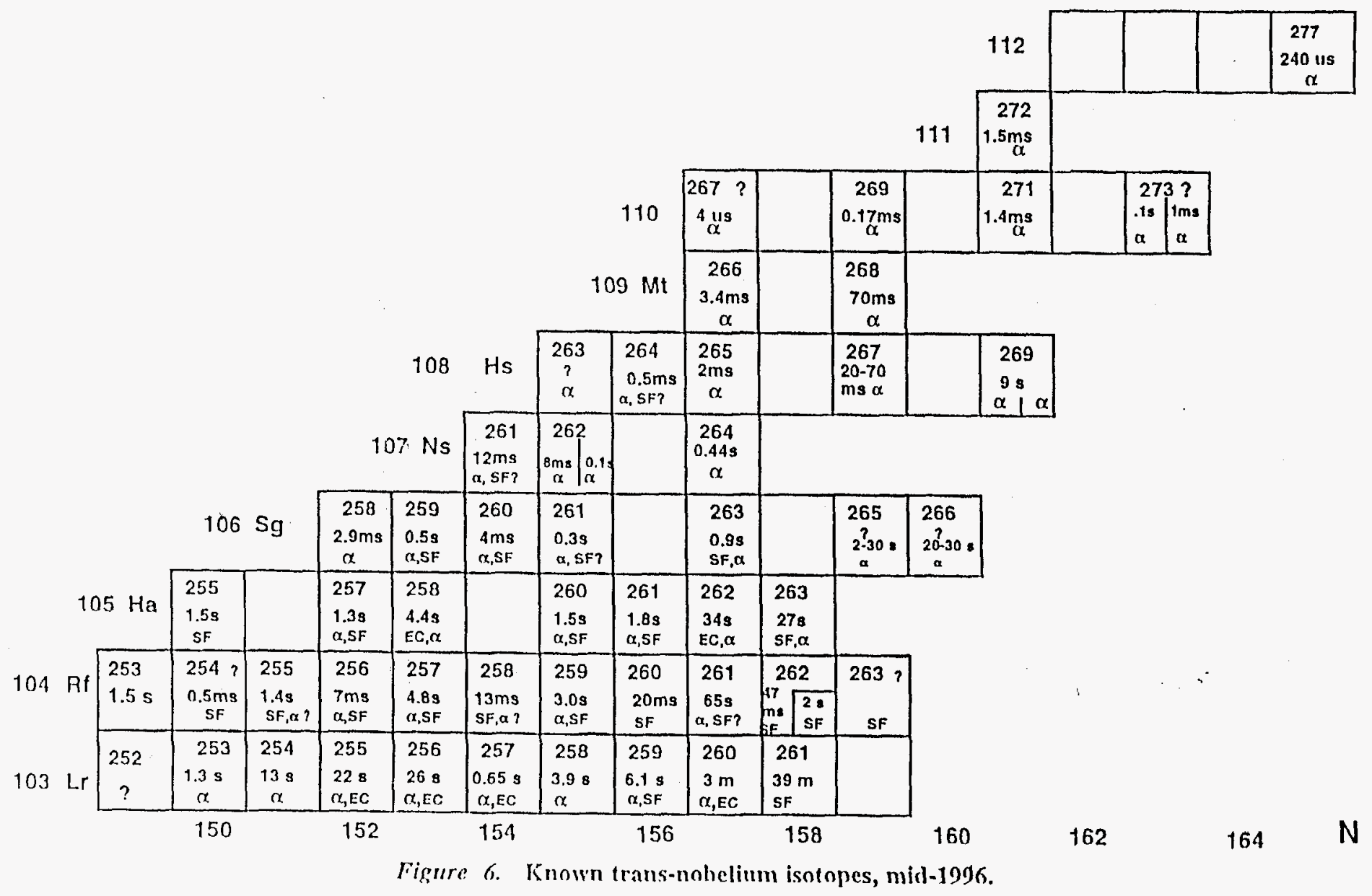

